\title{
PRELIMINARY STUDY ON THE EFFECT OF REPETITIVE TRANS- CRANIAL MAGNETIC STIMULATION ON NEGATIVE SYMPTOMS IN PATIENTS WITH SCHIZOPHRENIA
}

\author{
Nahla Nagy ${ }^{1}$,Soheir El Ghoniemy ${ }^{1}$,ShinsukeKito ${ }^{2}$,Marwa El Missiry ${ }^{1}$, Hussien \\ ElKholy ${ }^{1}$ and Shrief Yousry,
}

\begin{abstract}
:
Back Ground: Negative symptoms of schizophrenia have been

${ }^{1}$ Department of Neurology and Psychiatry, Faculty of Medicine, Ain Shams University, Egypt.

${ }^{2}$ Department of Psychiatry and Advanced Medical Technology, Japan.

Corresponding author:

Shrief Yousry Mohamed Mobile: 01003057195

E mail:

shierfyoussry@med.asu.edu.eg Received: 9/4/2019

Accepted:21/4/2019 demonstrated to be the most relevant predictor of increased future socio-occupational dysfunction and poorer quality of life which is linked to impaired functioning of the prefrontal cortex, mainly reduced activation of the dorsolateral prefrontal cortex. Repetitive Trans-cranial Magnetic Stimulation (rTMS) is a relatively safe and non-invasive tool to modulate neuronal activity. High-frequency rTMS might have role in improvement of negative symptoms of schizophrenia.

Aim of work: The Aim of this study to explore the effects of high frequency rTMS stimulation to the DLPFC on negative symptoms observed in schizophrenia patients.

Patients and Methods: 40 patients with schizophrenia who accept and there guardians to participate in the study and sign the written informed consent were assessed by Positive and Negative Syndrome Scale for Schizophrenia (PANSS), before the rTMS sessions and after the sessions. Meanwhile the operator allocated the subjects to active or sham group then the subjects of the study received active or Sham rTMS. The rTMS was delivered for 3 sessions /week during six weeks, each session lasts for 13 minutes.

Results: There was a statistical significance between active and sham group as regard PANSS Negative subdomain scale, used before and after the rTMS sessions (P value $=\mathbf{0 . 0 0 1}$ ) Also there was a statistical significant difference among active group before and after the rTMS stimulation( $P$ value $<0.001$ ).

Conclusion: This study suggests that high frequency rTMS applied to DLPFC may be of benefit in alleviating negative symptoms in schizophrenic patients. A larger sample size is needed to confirm our findings.

Key wards: Negative symptoms, schizophrenia, repetitive Trans Cranial Magnetic Stimulation (rTMS), Doros Lateral Prefrontal cortex (DLPFC), Electro convulsive Therapy (ECT) positive and negative syndrome scale (PANSS).
\end{abstract}

Role of researchers:

All authors contributed to the production for this manuscript. S.Y was responsible for the field work.

\section{INTRODUCTION:}

Negative symptoms of schizophrenia have been demonstrated to be the most relevant predictor of increased future sociooccupational dysfunction and poorer quality of life $\mathrm{e}^{(\mathbf{1})}$.

Impaired functioning of the prefrontal cortex, mainly reduced activation of the 
dorsolateral prefrontal cortex, has consistently been reported in patients with schizophrenia. Furthermore, there are growing evidences for a correlation between severity of negative symptoms and hypo functioning of the left dorsolateral prefrontal cortex $^{(2)}$.

Repetitive Trans-cranial Magnetic Stimulation (rTMS) is a relatively safe and non-invasive tool to modulate neuronal activity; rTMS uses alternating magnetic fields in a certain frequency to induce an electric current in the underlying brain tissue. High-frequency rTMS has been shown to increase local cortical excitability and low-frequency rTMS has been shown to decrease excitability ${ }^{(3)}$.

Administering high frequency rTMS to the left dorsolateral prefrontal cortex might increase brain activity in the stimulated area and to change brain activity in associated regions that are part of the same neural circuit which might improve negative symptoms of schizophrenia ${ }^{(4)}$.

\section{PATIENTS AND METHODS:}

\section{Type of the study:}

It is Randomized interventional study.

The study was approved by the ethical committee of faculty of medicine and registered under ID number FWA 000017585 also registered in Pan-African Clinical Trials Registry under Trail ID number 6066.

\section{Samplinq:}

Convenient sample from patients with negative symptoms was selected from the outpatient and inpatients in the institute of psychiatry, Ain Shams University hospital. All patients fulfilling the inclusion criteria were offered to participate in the study. For this preliminary study we have 2 groups active and sham group each of them has 20 subjects. Those patients who agreed to join the study were randomized to one of the 2 groups (active or sham) using closed envelops stating the group of the patient.

\section{Inclusion \& exclusion criteria:}

Male \& female Patients who were diagnosed to have schizophrenia according to DSM IV-TR and their age ranges between 18-45 years, with exclusion for patients who received ECT sessions at least 6 months before the start of the study. All patients kept on same medication regimen which already used for the whole duration of the repetitive rTMS sessions. The study excluded patients with any other medical or psychiatric illness, patients who previously treated with repetitive Trans- cranial magnetic stimulation, Pregnancy as well as patients with contraindications to rTMS as cardiac patient with pacemaker.

\section{Tools :}

\section{The Structured Clinical Interview for DSM IV-TR Axis-I disorders (SCIDI)}

- Description: The Structured Clinical Interview for DSM-IV Axis I Disorder (SCID-I) is a clinician-administered, semi-structured interview for use with psychiatric patients or with non-patient community subject, who are undergoing evaluation for psychopathology.

- Aim: The SCID-I was developed to provide broad coverage of psychiatric diagnosis according to DSM-IV TR. It was designed to be more efficient and simpler to use than other existing instruments and, consequently, to require less time for administration. It will be done for exclusion of comorbidities $^{(5)}$.

- We used the Arabic Version Translated by EL Missiry ${ }^{(6)}$.

Positive and Negative Syndrome Scale for Schizophrenia (PANSS):

- Description: There are seven items measuring positive symptoms, seven for 
negative symptoms and 16 items corresponding to general symptoms. The positive symptoms comprise of delusions, conceptual disorganization, hallucinations, hyperactivity, grandiosity, suspiciousness and hostility and together form a positive subscale. In the negative items, the symptoms blunted affect, emotional withdrawal, poor rapport, apathetic social withdrawal, difficulty in abstract thinking, lack of spontaneity and stereotyped thinking are included.

- Aim: The Positive and Negative Syndrome Scale is designed by combining two established rating systems, the Brief Psychiatric Rating Scale and the Psychopathology Rating Schedule, to assess the severity of positive and negative symptoms.

- Scoring: The PANSS consists of 30 items measuring specific symptoms, each item ranging from 1 (absent) to 7 (extreme), the higher the score, the worse the symptoms ${ }^{(7)}$.

\section{Repetitive Trans cranial magnetic stimulation (rTMS):}

\section{- Description:}

The rTMS was administered using a Magventure R 30 stimulator with a $75 \mathrm{~mm}$ figure-eight coil. Patients was stimulated at a frequency of $10 \mathrm{~Hz}$ in 100 trains with number of trains 20 with an inter-train interval of $15 \mathrm{~s}$ and the stimulation intensity was done at $90 \%$ of the motor threshold. The F3 location from the EEG 10-20 system was used to target the left dorsolateral pre-frontal cortex basing on the modifications of previous protocols used to study the effect of rTMS on negative symptoms of patients with schizophrenia ${ }^{(8)}$.

Also for placebo stimulation, the coil was tilted over left dorsolateral pre-frontal cortex without touching the scalp.
- Aim: The rTMS machine delivered a large current in a short period of time then produces a magnetic field which will induce an electric field sufficient to stimulate neurons or change the resting membrane potential in the underlying $\operatorname{cortex}^{(\mathbf{9})}$.

\section{Procedures:}

Subjects in both groups were conducted through clinical psychiatric interview according to standard patient psychiatric sheet of Institute of Psychiatry Ain Shams University, which examines demographic data, psychiatric history and examination as well as medical history information. Then subjects in both groups were subjected to full medical history and examination (general and neurological examinations). The diagnosis of schizophrenia was done according to DSM IV-TR classification using SCID I. After that Subjects were included if they had moderate to prominent negative symptoms, a negative sub-score equal or more than 15 on the Positive and Negative Syndrome Scale for Schizophrenia. The subjects of the study were assessed by Positive and Negative Syndrome Scale for Schizophrenia, before the rTMS sessions and after the sessions. Meanwhile the operator allocated the subjects to active or sham group then the subjects of the study received active or Sham rTMS which is noninvasive treatment, The repetitive trans cranial magnetic stimulation treatment was delivered for 3 sessions /week during six weeks, for a total of 18 treatment sessions, each session lasts for 13 minutes. Informed written consent was taken from patients and /or their caregivers. Finally after completing the both groups, the operator provided the researcher with a sheet clarifying the active group and the sham group.

Informed consent: An informed written consent was offered for the potential participants of the study. It contained the name of the study and its aim. It included 
detailed description of the procedure, the expected benefits.

The participants were informed that they have the right to withdraw from the study at any time without justification. And that their withdrawal will not affect in any way their treatment Plan, Moreover, they were informed that this study could be used for scientific publication without the disclosure of the participants' personal identity.

\section{Statistical Analysis:}

All data was recorded and entered in a statistical package on a compatible computer and varied. Analysis will use an SPSS- $21^{\text {th }}$ version $^{(\mathbf{1 0})}$.

\section{RESULTS:}

This study was done to assess the effect of rTMS on negative symptoms in patients with schizophrenia after receiving active TMS sessions combined to pharmacotherapy in comparison with sham group receiving pharmacotherapy as well as sham stimulation. The total number of participates was 46 participant, 6 was withdrawn, 4 of them refuse to continue the sessions and 2 of them were relapsed.

The collected data was revised, coded, tabulated and introduced to a PC using Statistical package for Social Science (SPSS 21). Data was presented and suitable analysis was done according to the type of data obtained for each parameter.

Table (1): Comparison between active and sham group as regard Socio demographic data:

\begin{tabular}{|c|c|c|c|c|c|c|c|}
\hline & \multicolumn{2}{|c|}{ Active } & \multicolumn{2}{|c|}{ Sham } & \multicolumn{2}{|c|}{ Test of sig. } \\
\hline & & Mean/N & $\mathrm{SD} / \%$ & Mean/ N & $\mathrm{SD} / \%$ & $p$ value & sig. \\
\hline Age & & 32.7 & 8.0 & 31.7 & 6.3 & 0.647 & $\mathrm{NS}$ \\
\hline \multirow[t]{2}{*}{ Sex } & Male & 18 & $90.0 \%$ & 18 & $90.0 \%$ & \multirow[t]{2}{*}{1} & \multirow[t]{2}{*}{$\mathrm{NS}$} \\
\hline & Female & 2 & $10.0 \%$ & 2 & $10.0 \%$ & & \\
\hline \multirow[t]{3}{*}{ Education } & High & 8 & $40.0 \%$ & 2 & $10.0 \%$ & \multirow[t]{3}{*}{0.065} & \multirow[t]{3}{*}{ NS } \\
\hline & Technical diploma & 11 & $55.0 \%$ & 17 & $85.0 \%$ & & \\
\hline & Read and write & 1 & $5.0 \%$ & 1 & $5.0 \%$ & & \\
\hline \multirow[t]{2}{*}{ Marital status } & Single & 15 & $75.0 \%$ & 14 & $70.0 \%$ & \multirow[t]{2}{*}{0.723} & \multirow[t]{2}{*}{ NS } \\
\hline & Married & 5 & $25.0 \%$ & 6 & $30.0 \%$ & & \\
\hline \multirow[t]{2}{*}{ Smoking } & Yes & 10 & $50.0 \%$ & 15 & $75.0 \%$ & \multirow[t]{2}{*}{0.102} & \multirow[t]{2}{*}{ NS } \\
\hline & No & 10 & $50.0 \%$ & 5 & $25.0 \%$ & & \\
\hline \multirow[t]{2}{*}{ Residence } & Urban & 17 & $85.0 \%$ & 16 & $80.0 \%$ & \multirow[t]{2}{*}{1} & \multirow[t]{2}{*}{ NS } \\
\hline & Rural & 3 & $15.0 \%$ & 4 & $20.0 \%$ & & \\
\hline \multirow[t]{3}{*}{ Antipsychotic } & Typical & 4 & $20.0 \%$ & 8 & $40.0 \%$ & \multirow[t]{3}{*}{0.134} & \multirow{3}{*}{ NS } \\
\hline & Atypical & 3 & $15.0 \%$ & 0 & $0.0 \%$ & & \\
\hline & Combined & 13 & $65.0 \%$ & 12 & $60.0 \%$ & & \\
\hline \multirow{3}{*}{$\begin{array}{l}\text { Duration of } \\
\text { Treatment }\end{array}$} & $<6$ months & 0 & $0.0 \%$ & 0 & $0.0 \%$ & \multirow[t]{3}{*}{1} & \multirow{3}{*}{ NS } \\
\hline & 6 months - 1 year & 1 & $5.0 \%$ & 0 & $0.0 \%$ & & \\
\hline & $>1$ year & 19 & $95.0 \%$ & 20 & $100.0 \%$ & & \\
\hline \multirow[t]{2}{*}{ relapse number } & No & 1 & $5.0 \%$ & 0 & $0.0 \%$ & \multirow[t]{2}{*}{1} & \multirow[t]{2}{*}{ NS } \\
\hline & 1 or more & 19 & $95.0 \%$ & 20 & $100.0 \%$ & & \\
\hline \multirow{2}{*}{$\begin{array}{l}\text { Hospitalization } \\
\text { before more than } \\
\text { once }\end{array}$} & Yes & 19 & $95.0 \%$ & 20 & $100.0 \%$ & \multirow[t]{2}{*}{1} & \multirow[t]{2}{*}{ NS } \\
\hline & No & 1 & $5.0 \%$ & 0 & $0.0 \%$ & & \\
\hline
\end{tabular}

Table (1) Shows that there was no statistical significance between active and sham group as regard socio demographic data. 
Table (2): Comparison between active and Sham group at week 6 (end of sessions)) as regard PANSS Negative subdomain scale:

\begin{tabular}{|l|c|c|c|c|c|c|c|}
\hline & \multicolumn{2}{|c|}{ Active } & \multicolumn{2}{c|}{ Sham } & \multicolumn{3}{c|}{ Mann Whitney test } \\
\cline { 2 - 8 } & Median & IQR & Median & IQR & Z & p value & sig. \\
\hline PANSS N(6) & 2 & $2-3$ & 4 & $4-5$ & -5.19 & $<0.001$ & S \\
\hline
\end{tabular}

Table (2) shows that there was a statistical significance between active and sham group as regard PANSS Negative subdomain scale .

Table (3): Comparison among active and sham group subjects before and after the repetitive Trans Cranial Magnetic Stimulation sessions (rTMS):

\begin{tabular}{|c|c|c|c|c|c|c|c|}
\hline \multirow[t]{2}{*}{ Active group } & \multicolumn{2}{|c|}{0 week (before) } & \multicolumn{2}{|c|}{$6^{\text {th }}$ week (after) } & \multicolumn{3}{|c|}{$\begin{array}{c}\text { Wilcoxon Signed Rank } \\
\text { test }\end{array}$} \\
\hline & Median & IQR & Median & IQR & $\mathrm{Z}$ & $p$ value & sig \\
\hline PANSS N & 4.0 & $4-4$ & 2.0 & $2-3$ & -4.06 & $<0.001$ & $\mathrm{~S}$ \\
\hline \multirow[t]{2}{*}{ Sham group } & \multicolumn{2}{|c|}{0 week (before) } & \multicolumn{2}{|c|}{$6^{\text {th }}$ week (after) } & \multicolumn{3}{|c|}{$\begin{array}{c}\text { Wilcoxon Signed Rank } \\
\text { test }\end{array}$} \\
\hline & Median & IQR & Median & IQR & $\mathrm{Z}$ & $\mathrm{p}$ value & sig \\
\hline PANSS N & 4.0 & $4-5$ & 4.0 & $4-5$ & 0 & 1.000 & NS \\
\hline
\end{tabular}

Table (3) showed a statistical significant difference among active group (P value $<0.001)$ while no statistical significance among sham group $(\mathrm{P}$ value $=1)$.

Table (4): Comparison between active and Sham group as regard the percent of changeas regard PANSS Negative subdomain scale:

\begin{tabular}{|c|c|c|c|c|c|c|c|c|}
\hline \multirow{2}{*}{\multicolumn{2}{|c|}{ CHANGE }} & \multicolumn{2}{|c|}{ Active } & \multicolumn{2}{|c|}{ Sham } & \multicolumn{3}{|c|}{ Test of sig. } \\
\hline & & $\mathrm{N}$ & $\%$ & $\mathrm{~N}$ & $\%$ & Statistics & $\mathrm{p}$ value & sig. \\
\hline \multirow{3}{*}{ PANSS(N) } & The same & 0 & $0.0 \%$ & 20 & $100.0 \%$ & \multirow{3}{*}{$X 2=40$} & \multirow{3}{*}{$<0.001$} & \multirow{3}{*}{$\mathrm{S}$} \\
\hline & Decreased & 20 & $100.0 \%$ & 0 & $0.0 \%$ & & & \\
\hline & Decreased & 0 & $0.0 \%$ & 1 & $5.0 \%$ & & & \\
\hline
\end{tabular}

Table (4) which showed thecomparison between both groupsas regard the percentage of change in PANSS negative subdomain showed statistical significant difference $(\mathrm{P}$ value $<0.001$ ).

\section{DISCUSSION:}

To our knowledge, no available Egyptian study had assessed the effect of rTMS in negative symptoms of patients with schizophrenia.

This study aims to extend our knowledge about the effect of the rTMS in negative symptoms of patients with schizophrenia after receiving active high frequency rTMS combined to pharmacotherapy in comparison to control group who diagnosed with schizophrenia and received sham rTMS as well as pharmacotherapy.

\section{I) Socio-demographic data:}

The total number of participants was 46 , 6 withdrew, 4 of them refused to continue the sessions and preferred pharmacotherapy only and 2 of them relapsed into active episode thus had to be excluded. They were divided into 2 groups; case group consist of 20 patients who received active rTMS sessions as well as the pharmacotherapy and control group of 20 patients who received Sham rTMS sessions as well as pharmacotherapy.

The mean age for case group was 32.7 years while for control group was 31.7 years which could be explained in the context that 
schizophrenia is disorder affecting adolescent and adulthood.

Most of our participant was single which agree with Mostafa and his colleagues who studied the socio demographic factors and different factors affecting adherence to treatment in Egyptian patients with schizophrenia which could be understood in poor social functioning noticed in patients with schizophrenia. ${ }^{(11)}$

The main level education for both groups was Technical diploma which is matched with the typical education level for our patients who visit our hospital.

More than 50 percent of our participants were cigarrate smokers in agreement with Smucny and Tregellas and Elkholy and his colleagues which may be understood in the context of the possible reduction in nicotinic receptor signaling which is associated with schizophrenia, and cigarette smoking could be a form of self-medication. ${ }^{(12,13)}$

More than 60 percent of the participants were treated by typical as well as atypical antipsychotic in agreement with Mostafa and his colleagues mostly due to the use depot antipsychotic to ensure the compliance of the patients.

Finally more than 95 percent of our participant received medications for more than 1 year, hospitalized before more than once in agreement with Abd Al-Hadi who studies the correlation between the quality of life and clinical variables among outpatients with schizophrenia which could be understood in the context of the natural relapsing course of the schizophrenia disorder, increasing in the severity of the subsequent relapses and the need for the long term treatment. ${ }^{(14)}$

\section{II) Negative Symptoms:}

Many studies tried to address the effect of rTMS on negative symptoms of patients with schizophrenia using different stimulation protocols; some got positive results with other did not. $(15,16,17)$

There was a statistical significance in PANSS negative subdomain score between Active and Sham group after receiving rTMS sessions which might be understood in the context of the positive effect of the active sessions in improving the negative symptoms in patient with schizophrenia in agreement with André and his colleagues and Wen and his colleagues who did a double blinded randomized controlled trial to detect the effect of non-invasive brain stimulation mainly rTMS for improving negative symptoms in schizophrenia. ${ }^{(18,19)}$

While Maximilian and his colleagues did not find any improving on PANSS negative total score which could be explained by using different stimulation protocol and different number of rTMS sessions. ${ }^{(15)}$

\section{Recommendations:}

Assessment of type and severity of negative symptoms in patients with schizophrenia should be put in consideration in the clinical assessment. With early intervention to enhance the prognosis of those patients to reach the concept of functional recovery which can be done throw Special treatment program formed of appropriate pharmacotherapy, psychotherapy as well as add on rTMS sessions for patients with negative symptoms of schizophrenia.

\section{Limitation:}

Assessment of improvement in the negative symptoms in the patients based only on psychometric tool which is not linked with radiological finding. Also Small sample size and the Place of study which focus on only patients with schizophrenia who visit tertiary level hospital in Cairo.

\section{Declaration:}

\section{All authors declared no conflict of interest}




\section{REFERENCES:}

1. Chue P and Lalonde C (2014): Addressing the unmet needs of patients with persistent negative symptoms of schizophrenia: emerging pharmacological treatment options. Neuropsychiatr. Dis. Treat. 10, 777-789.

2. Yunzhe L, Dandan Z, et al. (2016): Deficits in attentional processing of fearful facial expressions in schizophrenic patients. Scientific Reports , 6: 32-594.

3. Alexander V, Andery Y, et al. (2015): Possible mechanisms underlying the therapeutic effects of transcranial magnetic stimulation.Front. Hum. Neurosci., 16: 1-7.

4. Thomas W, Birgit G, et al. (2014): Left Prefrontal High-Frequency Repetitive Transcranial Magnetic Stimulation for the Treatment of Schizophrenia with Predominant Negative Symptoms: A ShamControlled, Randomized Multicenter Trial. biopsych, 10:1-9.

5. First M, Spitzer R, et al. (1996):Structured clinical interview for DSM-IV axis I disorders, clinician version (SCID-CV). Washington, DC: American Psychiatric Press.

6. El Missiry A. (2003): Homicide and Psychiatric Illness, An Egyptian Study. MD thesis Faculty of Medicine, Ain Shams University.

7. Kay S, Fiszbein A, et al. (1987): The positive and negative syndrome scale (PANSS) for schizophrenia. Schizophr. Bull. 13 (2): 261-276.

8. Beam, W, Borckardt J, et al. (2009): An efficient and accurate new method for locating the $\mathrm{F} 3$ position for prefrontal TMS applications. Brain Stimul. 2 (1), 50-54.

9. Post A and Keck M (2001): Trans cranial magnetic stimulation as a therapeutic tool in psychiatry: what do we know about the neurobiological mechanisms?JPsychiatr Res, 35:193-215.
10. IBM Corp. (2012): IBM SPSS Statistics for Windows, Version 21.0. Armonk, NY: IBM Corp.

11. Mostafa A, Ahmed E, et al. (2013): Adherence in Egyptian patients with schizophrenia: the role of insight, Medication beliefs and spirituality, The Arab Journal of Psychiatry, 1: 60-68.

12. Smucny J and Tregellas J (2017): Targeting neuronal dysfunction in schizophrenia with nicotine: evidence from neurophysiology to neuroimaging. J. Psychopharmacol, 31 (7): 801-811.

13. Elkholy H, Nagy N, et al. (2019): Stop Turning a Blind Eye: Tobacco Smoking Among Egyptian Patients With Schizophrenia, Front. Psychiatry,9,703.

14. Abd Al-Hadi H (2019): The correlation between the quality of life and clinical variables among outpatients with schizophrenia, Psychiatry Research,271, 3945.

15. Maximilian H, Thomas W, et al. (2018): Efficacy of high-frequency repetitive trans cranial magnetic stimulation on PANSS factors in schizophrenia with predominant negative symptoms - Results from an exploratory re-analysis. Psychiatry Research, 263: 22-29.

16. He H, Lu J, et al. (2017): Repetitive Trans cranial magnetic stimulation for treating the symptoms of schizophrenia: a PRISMA compliant meta-analysis. Clin. Neurophysiol, 128: 716-724.

17. Fusar P, Papanastasiou E, et al. (2015): Treatments of negative symptoms in schizophrenia: meta-analysis of 168 randomized placebo-controlled trials. Schizophr Bull, 41: 892-899.

18. André A, Stefanie E, et al. (2018): Moderate effects of noninvasive brain stimulation of the frontal cortex for improving negative symptoms in schizophrenia: Meta-analysis of controlled trials, Neuro science and behavioral review, 89: 111-118. 
دراسه تمهيدية عن تاثير التتبيه المغناطيسى المتكرر عبرة القثرة المخية على الاعراض السلبية لمرضى الفصام

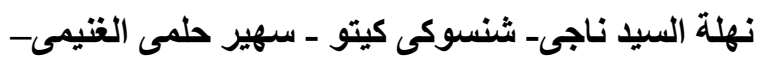

مروة عادل المسيرى - حسين احمد الخولى لتصويل

شريف يسرى محمد

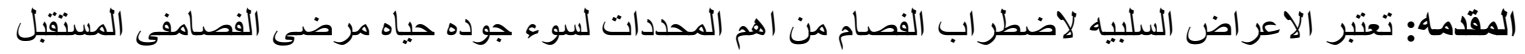

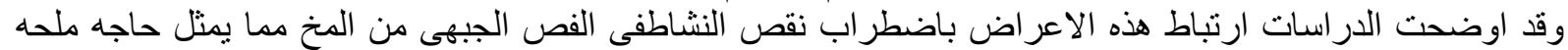

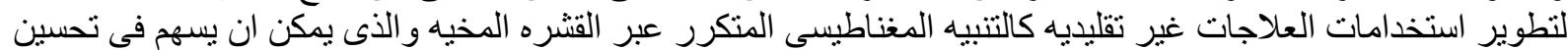
الاعر اض السلبيه لاضطر اب الفصام الفير

الغرض من الاراسة: تحديد تاثير التنبيه المغناطيسى المتكرر عبر القشره المخيه على منطقه الفص الجبهى على لإصى

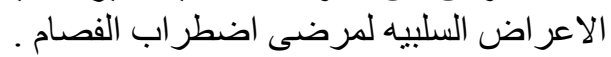

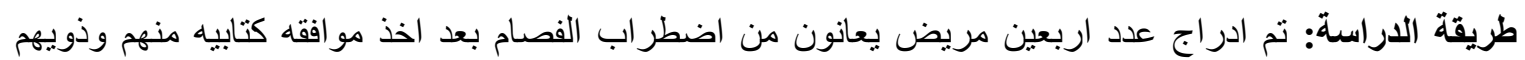

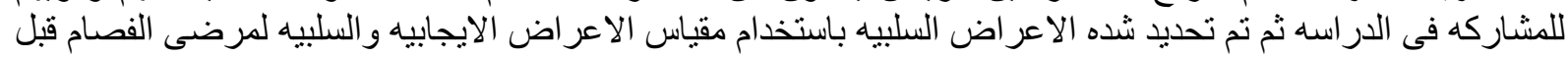

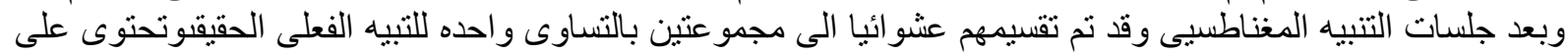
عشرين مريض و الاخرى للتنبيه الغير حقيقى و عددهم عشرين مريض ايضا وقد تم اعطاء عدد ثلاث جلسات في الاسبو

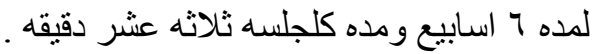

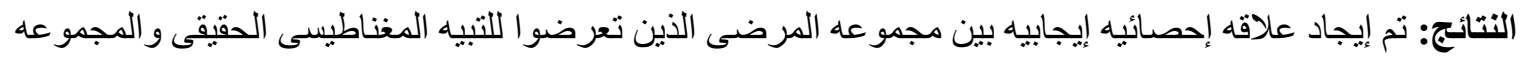

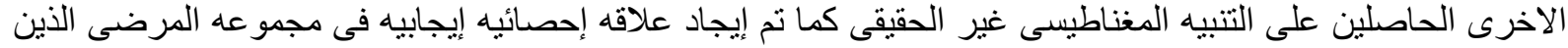
تعرضو ا للتبيه المغناطيسى الحقيقى قبل وبعد الجلسات .

الخاتمة: إن الدر اسه الحاليه تستنج احتماليه وجود فائده من التبيه المغناطيسى المتكرر عبر القتره المخيه فى تحسين

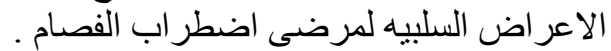

